\title{
Manejo de plantas daninhas em milho safrinha em cultivo solteiro ou consorciado à braquiária ruziziensis
}

\author{
Fernando Storniolo Adegas ${ }^{(1)}$, Elemar Vol( ${ }^{(1)}$ e Dionísio Luiz Pisa Gazziero(1) \\ (1)Embrapa Soja, Caixa Postal 231, CEP 86001-970 Londrina, PR. E-mail: adegas@cnpso.embrapa.br, voll@cnpso.embrapa.br, \\ gazziero@cnpso.embrapa.br
}

\begin{abstract}
Resumo - O objetivo deste trabalho foi avaliar a eficiência de herbicidas pós-emergentes no controle das plantas daninhas, e sua seletividade à braquiária (Urochloa ruziziensis) e ao milho safrinha, em cultivo solteiro ou consorciado. O experimento foi conduzido em delineamento de blocos ao acaso, com quatro repetições, em esquema fatorial 2x14: cultivo do milho consorciado ou não à braquiária e 14 tratamentos químicos, além de duas testemunhas, com ou sem controle das plantas daninhas. Avaliou-se o controle das plantas daninhas, a fitotoxicidade para braquiária e a produtividade do milho. Todos os tratamentos com herbicidas proporcionaram controle acima de $80 \%$ das plantas daninhas aos 14 dias após a aplicação. As misturas formuladas de atrazina+óleo, a 800 e a $1.200 \mathrm{~g} \mathrm{ha}^{-1}$, compuseram o grupo de herbicidas mais seletivos a U. ruziziensis; o grupo de menor seletividade consistiu da aplicação isolada de tembotrione ou de suas associações com atrazina. A competição com a braquiária reduziu a produtividade do milho em até 45,3\%. Contudo, não houve diferença entre os tratamentos nas parcelas tratadas com herbicidas.
\end{abstract}

Termos para indexação: Brachiaria, Urochloa ruziziensis, consorciação, fitotoxicidade, herbicidas.

\section{Weed management in off-season corn cropped alone or intercropped with Congo signal grass}

\begin{abstract}
The objective of this work was to evaluate the efficiency of post-emergence herbicides for weed control, and its selectivity to Congo signal grass (Urochloa ruziziensis) and to off-season corn cropped alone or intercropped. The trial was carried out in randomized blocks with four replicates in a 2x14 factorial design: off-season corn intercropped or not to U. ruziziensis, and 14 different treatments with herbicides, besides two tests with or without weed control. Weed control, herbicide phytotoxicity to U. ruziziensis, and corn yield were evaluated. All herbicide treatments provided weed control over $80 \%$ at 14 days after the application. The treatments with atrazine+oil, at 800 and $1,200 \mathrm{~g} \mathrm{ha}^{-1}$, formed the most selective group to U. ruziziensis; the group with the lowest selectivity consisted of the application of tembotrione alone and in associations with atrazine. The competition between $U$. ruziziensis and corn reduced corn yield up to $45.3 \%$. However, there were no differences between treatments in the plots treated with herbicides.
\end{abstract}

Index terms: Brachiaria, Urochloa ruziziensis, intercropping, phytotoxicity, herbicides.

\section{Introdução}

O Brasil é um dos poucos países em que é possível realizar o cultivo de mais de uma cultura de grãos por ano na mesma área, como é o caso da sucessão soja [Glycine max (L.) Merr.] e milho safrinha (Zea mays L.), cuja exploração está concentrada nos estados de Goiás, Mato Grosso, Mato Grosso do Sul e Paraná. Anualmente, cultivam-se cerca de 5 milhões de hectares com esta sucessão, o que representa $34,7 \%$ da área cultivada com milho no país (Companhia Nacional de Abastecimento, 2009), e revela a importância desse sistema de produção de grãos para a agricultura nacional.

No entanto, a produção contínua de grãos no sistema soja e milho safrinha pode não ser sustentável, principalmente por problemas com o manejo do solo relativos à baixa cobertura com palha e à redução do teor de matéria orgânica, que aumentam a suscetibilidade à erosão hídrica e as perdas de água por evaporação, e resultam em maior compactação do solo (Beutler \& Centurion, 2004). Há também o aumento da suscetibilidade dessas culturas a períodos de estiagem, com diminuição da produtividade (Franchini et al., 2008). No sistema de produção com sucessão, o investimento no controle das plantas daninhas na cultura do milho safrinha, é normalmente baixo, o que resulta no aumento da flora infestante e do banco de sementes de invasoras.

Uma alternativa para minimizar os impactos negativos da sucessão soja-milho seria a introdução do cultivo de plantas de cobertura, especialmente de

Pesq. agropec. bras., Brasília, v.46, n.10, p.1226-1233, out. 2011 
forrageiras, após a colheita do milho safrinha ou em cultivo consorciado ao milho (Torres \& Saraiva, 1999). Há também a possibilidade da cultura consorciada ser produzida com a finalidade de forrageira, para ser utilizada na alimentação animal ou servir de cobertura para o solo, o que aumenta a rentabilidade geral do sistema de produção de grãos com base na sucessão soja-milho safrinha (Ceccon, 2007).

Em sistemas consorciados de produção, no entanto, as espécies utilizadas estão sujeitas à competição entre si, além da matocompetição naturalmente exercida pelas plantas daninhas, o que torna fundamental planejar corretamente o manejo com herbicidas na área, para controlar as plantas daninhas e suprimir apenas parcialmente a forrageira (Macedo, 2009). O objetivo, neste caso, é o de evitar perdas na produção do milho ou da cultura consorciada pela competição com as plantas daninhas.

As forrageiras tropicais, sobretudo as braquiárias, como a Urochloa ruziziensis (A. Rich.) R.D. Webster (Syn. Brachiaria ruziziensis), têm sido estudadas em consórcio com o milho safrinha, com bons resultados para cobertura do solo e alimentação animal (Ceccon et al., 2008). Contudo, para evitar perdas de produção no milho, é necessário manejar adequadamente a braquiária, o que inclui ajustar a densidade de semeadura (Bernardes, 2003) e realizar a correta supressão da forrageira com a aplicação de herbicidas (Jakelaitis et al., 2005b; Freitas et al., 2008). Se a braquiária não for devidamente manejada, pode ocorrer diminuição da produtividade do milho, conforme trabalhos de Portes et al. (2000) e Jakelaitis et al. (2005a).

Atualmente, o manejo químico de plantas daninhas na cultura do milho safrinha é realizado basicamente pela aplicação de atrazina, que controla principalmente infestantes dicotiledôneas (Rodrigues \& Almeida, 2005). Contudo, nessa época de cultivo, é normal também a ocorrência de infestantes monocotiledôneas, como mostraram os levantamentos de Duarte et al. (2007), para a região Sudeste, e de Brighenti et al. (2003) e Adegas (2005), para a região Centro-Oeste. Portanto, tem sido necessário o uso de herbicidas graminicidas, que possuem ação sobre essas espécies, sobretudo em pós-emergência. Embora o nicosulfuron seja o herbicida mais utilizado, recentemente foram registrados outros herbicidas passíveis de serem usados nessas situações, como o mesotrione e o tembotrione (Brasil, 2010).
Para a consolidação da tecnologia de consórcio entre o milho safrinha e a U. ruziziensis, é fundamental aprimorar o conhecimento sobre a utilização dos herbicidas nesse sistema, principalmente os de ação graminicida, com análise das consequências para as culturas em consórcio e para as plantas daninhas.

O objetivo deste trabalho foi avaliar o uso de herbicidas pós-emergentes no controle das plantas daninhas, e sua seletividade para Urochloa ruziziensis em consórcio com o milho safrinha.

\section{Material e Métodos}

O experimento foi realizado em 2009, em Londrina, PR (231' $19 " \mathrm{~S}, 51^{\circ} 10^{\prime} 53^{\prime \prime} \mathrm{W}$, a $587 \mathrm{~m}$ de altitude), em um Latossolo Vermelho eutroférrico, com $74 \%$ de argila e $2,4 \%$ de matéria orgânica, após a colheita da soja .

Utilizou-se o delineamento experimental de blocos ao acaso, com quatro repetições, em esquema fatorial 2x14: milho safrinha consorciado ou não com $U$. ruziziensis e 14 tratamentos químicos, além de duas testemunhas, com ou sem controle manual das plantas daninhas. Os tratamentos químicos, com os nomes técnicos dos herbicidas e as dosagens utilizadas estão descritos na Tabela 1.

No dia 4/3/2009, foi realizada a semeadura das parcelas que continham U. ruziziensis, com distribuição a lanço das sementes e posterior incorporação superficial com grade niveladora. No mesmo dia, foi realizada a semeadura do híbrido simples de milho BRS 1030 em todo o experimento, com espaçamento entre linhas de $0,90 \mathrm{~m}$ e densidade de sete plantas por metro. As parcelas experimentais foram compostas por seis linhas de milho, com dimensão de 5,4x6,0 m e área útil de $14,4 \mathrm{~m}^{2}$.

Antes da aplicação dos herbicidas, foi realizada a contagem do número de plantas daninhas e de $U$. ruziziensis, com o uso de um quadrado de ferro de $0,5 \times 0,5 \mathrm{~m}$, em quatro amostragens aleatórias, o que totalizou $1,0 \mathrm{~m}^{2}$ amostrado por parcela.

As aplicações foram realizadas com pulverizador costal pressurizado por $\mathrm{CO}_{2}$, à pressão constante de $276 \mathrm{kPa}$, equipado com barra de 3,0 $\mathrm{m}$ de largura efetiva e seis pontas de pulverização do tipo jato plano DG 110.02, distanciadas em 0,5 m, com volume de pulverização equivalente a $190 \mathrm{~L} \mathrm{ha}^{-1}$. As condições meteorológicas foram consideradas satisfatórias, com temperatura entre 21,9 e $23,9^{\circ} \mathrm{C}$, umidade relativa entre 
58 e $69 \%$ e vento máximo de $4,9 \mathrm{~km} \mathrm{~h}^{-1}$. No momento da aplicação, constatou-se estádio fenológico V4 para o milho, U. ruziziensis em início de perfilhamento e plantas daninhas monocotiledôneas e dicotiledôneas com duas a seis folhas verdadeiras.

A avaliação de controle das plantas daninhas e da seletividade dos herbicidas para o milho safrinha foi realizada pela comparação visual com a testemunha sem controle, por meio de dois parâmetros: individualmente por espécie e pelo conjunto da população presente nas parcelas aos 7, 14, 28 e 42 dias após a aplicação (DAA). Foi utilizada escala percentual, em que zero $(0 \%)$ representa a ausência de sintomas de fitotoxicidade e 100\% a morte das plantas (Asociación Latinoamericana de Malezas, 1974). Para a cultura do milho, foi avaliado também o rendimento de grãos do milho, por meio da colheita da área útil das parcelas.

A metodologia de avaliação da seletividade dos herbicidas a U.ruziziensis foi a mesma utilizada para a cultura do milho, inclusive com avaliação nas mesmas épocas. Além dessa avaliação, foi realizada a medição da biomassa seca total da população de $U$. ruziziensis pela coleta das plantas presentes em 1,0 $\mathrm{m}^{2}$ de cada parcela, na época da colheita da cultura, com uso do quadrado de ferro de $0,5 \times 0,5 \mathrm{~m}$. A secagem foi realizada em estufa de circulação forçada de ar a $70 \pm 1^{\circ} \mathrm{C}$, até atingir peso constante, e pesagem em balança de precisão.

Os resultados obtidos foram submetidos à análise de variância, e as médias foram agrupadas pelo teste

Tabela 1. Descrição dos tratamentos aplicados no milho safrinha consorciado com Urochloa ruziziensis.

\begin{tabular}{lcc}
\hline Sigla do Tratamento & Tratamento \\
\cline { 2 - 3 } & Nome Comum & Dose $\left(\mathrm{g} \mathrm{ha}^{-1}\right)$ \\
\hline Mes+Atr (60+800) & Mesotrione + (Atrazina+Óleo) & $60+800$ \\
Mes+Atr $(90+800)$ & Mesotrione + (Atrazina+Óleo) & $90+800$ \\
Mes+Atr $(120+800)$ & Mesotrione + (Atrazina+Óleo) & $120+800$ \\
Mes+Atr $(60+1.200)$ & Mesotrione + (Atrazina+Óleo) & $60+1.200$ \\
Atr $(800)$ & (Atrazina+Óleo) & 800 \\
Atr $(1.200)$ & (Atrazina+Óleo) & 1.200 \\
Tem $(75)$ & Tembotrione & $75,6^{(1)}$ \\
Tem $(100)$ & Tembotrione & $100,8^{(1)}$ \\
Tem+Atr $(50+1.000)$ & Tembotrione + Atrazina & $50,4+1.000^{(1)}$ \\
Tem+Atr $(75+1.000)$ & Tembotrione + Atrazina & $75,6+1.000^{(1)}$ \\
Nic+Atr $(16+800)$ & Nicosulfuron + (Atrazina+Óleo) & $16+800$ \\
Nic+Atr $(20+800)$ & Nicosulfuron + (Atrazina+Óleo) & $20+800$ \\
Tcap & Testemunha capinada & - \\
Tsem & Testemunha sem capina & - \\
\hline
\end{tabular}

${ }^{(1)}$ Adicionado o adjuvante Áureo, a $0,5 \% \mathrm{v} / \mathrm{v}$. de Scott-Knott, a 5\% de probabilidade, exceto na comparação da produtividade do milho com ou sem $U$. ruziziensis, em que utilizou-se o teste t, a $5 \%$ de probabilidade.

\section{Resultados e Discussão}

A flora infestante do experimento apresentou densidade de 28,4 plantas daninhas $\mathrm{m}^{-2}$, com as seguintes espécies presentes: Ageratum conyzoides L. (7,9 plantas $\left.\mathrm{m}^{-2}\right)$, Amaranthus hybridus L. (11,0 plantas $\left.\mathrm{m}^{-2}\right)$, Commelina benghalensis L. (1,8 plantas $\left.\mathrm{m}^{-2}\right)$, Digitaria horizontalis Willd. (3,9 plantas $\left.\mathrm{m}^{-2}\right)$, Raphanus raphanistrum L. $\left(1,4\right.$ plantas $\left.\mathrm{m}^{-2}\right)$ e Richardia brasiliensis Gomes (2,4 plantas $\left.\mathrm{m}^{-2}\right)$. Não houve significância pelo teste $\mathrm{F}$ para o fator de controle das plantas daninhas com ou sem U. ruziziensis; por isso, os resultados de controle estão apresentados apenas com as médias gerais do conjunto da população infestante, dentro do fator referente ao tratamento químico (Tabela 2).

Na primeira avaliação, aos sete DAA, os tratamentos Mes+Atr $\left(90+800 \mathrm{~g} \mathrm{ha}^{-1}\right)$, Mes+Atr $\left(60+1.200 \mathrm{~g} \mathrm{ha}^{-1}\right)$, Tem $\left(75 \mathrm{~g} \mathrm{ha}^{-1}\right)$, Tem+Atr $\left(50+1.000 \mathrm{~g} \mathrm{ha}^{-1}\right)$ e Tem+Atr $\left(75+1.000 \mathrm{~g} \mathrm{ha}^{-1}\right)$ formaram o grupo de maior eficácia de controle, com média acima de 87\% (Tabela 2). Estes tratamentos foram compostos pelos herbicidas mesotrione ou tembotrione, que pertencem ao grupo químico das tricetonas, cujo mecanismo de ação é a inibição da enzima 4-hidroxifenil-piruvato-dioxigenase, conhecida como HPPD (Senseman, 2007). Williams \& Pataky (2008) relataram que, após a absorção desses herbicidas pelas plantas, os sintomas de fitotoxicidade aparecem rapidamente nas espécies sensíveis, o que foi comprovado neste trabalho (Tabelas 2 e 3 ). A mesma velocidade no aparecimento dos sintomas de fitotoxicidade não ocorreu com os outros dois herbicidas testados, pois tanto o nicosulfuron, cujo mecanismo de ação é a inibição da enzima acetolactato sintase (ALS), como a atrazina, que atua na inibição do fotossistema II, tem os sintomas mais lentamente desenvolvidos nas aplicações em pós-emergência (Christoffoleti et al, 2003).

$\mathrm{Na}$ avaliação aos $14 \mathrm{DAA}$, todos os tratamentos de herbicidas proporcionaram controle satisfatório das plantas daninhas, com índice igual ou acima de 80\% (Tabela 2). Com o aumento do período após 
as aplicações, o controle das infestantes aumentou, tendo o seu ápice aos 28 DAA. As exceções foram as aplicações isoladas de atrazina, que tiveram os resultados diminuídos em comparação à avaliação anterior, principalmente pelo rebrote das plantas de $C$. benghalensis e pelo controle insatisfatório de $D$. horizontalis, o que comprova a baixa eficácia deste herbicida para o controle de monocotiledôneas (Karam \& Melhorança, 2009).

$\mathrm{Na}$ última avaliação, aos $42 \mathrm{DAA}$, o grupo de tratamentos com maior eficácia de controle foi formado por Mes+Atr $\left(90+800 \mathrm{~g} \mathrm{ha}^{-1}\right)$, Tem (100 $\left.\mathrm{g} \mathrm{ha}^{-1}\right)$, Tem+Atr $\left(50+1.000 \mathrm{~g} \mathrm{ha}^{-1}\right)$ e Tem+Atr $\left(75+1.000 \mathrm{~g} \mathrm{ha}^{-1}\right)$, que não diferiram da testemunha capinada. Na sequência de eficácia, comíndices ainda considerados satisfatórios, entre 83,7 e $90 \%$, ficaram os demais tratamentos com os herbicidas mesotrione, nicosulfuron e tembotrione e suas associações com atrazina. Esse resultado corrobora os de Karam \& Cruz (2004) e Karam et al. (2009), que afirmam que o mesotrione e o tembotrione controlam adequadamente as espécies $A$. conyzoides, $A$. hybridus, $C$. benghalensis, D. horizontalis, $R$. raphanistrum e R. brasiliensis.

Tabela 2. Controle percentual de plantas daninhas aos 7 , 14, 28 e 42 dias após a aplicação (DAA) dos herbicidas na cultura do milho safrinha consorciado com Urochloa ruziziensis ${ }^{(1)}$.

\begin{tabular}{lrrrr}
\hline Tratamento $^{(2)}$ & \multicolumn{4}{c}{ Controle (\%) $)^{(3)}$} \\
\cline { 2 - 5 } & 7 DAA & 14 DAA & 28 DAA & $42 \mathrm{DAA}$ \\
\hline Mes+Atr (60+800) & $80,0 \mathrm{~b}$ & $86,7 \mathrm{~b}$ & $90,0 \mathrm{~b}$ & $87,5 \mathrm{~b}$ \\
Mes+Atr $(90+800)$ & $90,7 \mathrm{a}$ & $95,0 \mathrm{a}$ & $99,0 \mathrm{a}$ & $95,0 \mathrm{a}$ \\
Mes+Atr $(120+800)$ & $82,5 \mathrm{~b}$ & $83,7 \mathrm{~b}$ & $88,7 \mathrm{~b}$ & $86,2 \mathrm{~b}$ \\
Mes+Atr (60+1.200) & $92,0 \mathrm{a}$ & $90,0 \mathrm{~b}$ & $90,7 \mathrm{~b}$ & $88,2 \mathrm{~b}$ \\
Atr (800) & $68,7 \mathrm{c}$ & $80,0 \mathrm{~b}$ & $76,2 \mathrm{c}$ & $66,7 \mathrm{c}$ \\
Atr (1.200) & $76,2 \mathrm{~b}$ & $85,0 \mathrm{~b}$ & $80,0 \mathrm{c}$ & $73,7 \mathrm{c}$ \\
Tem (75) & $87,5 \mathrm{a}$ & $90,2 \mathrm{~b}$ & $91,2 \mathrm{~b}$ & $90,0 \mathrm{~b}$ \\
Tem (100) & $81,2 \mathrm{~b}$ & $91,0 \mathrm{~b}$ & $95,0 \mathrm{a}$ & $92,5 \mathrm{a}$ \\
Tem+Atr $(50+1.000)$ & $89,2 \mathrm{a}$ & $93,7 \mathrm{a}$ & $94,7 \mathrm{a}$ & $93,0 \mathrm{a}$ \\
Tem+Atr $(75+1.000)$ & $90,7 \mathrm{a}$ & $98,2 \mathrm{a}$ & $98,2 \mathrm{a}$ & $97,5 \mathrm{a}$ \\
Nic+Atr (16+800) & $68,7 \mathrm{c}$ & $85,0 \mathrm{~b}$ & $90,0 \mathrm{~b}$ & $83,7 \mathrm{~b}$ \\
Nic+Atr (20+800) & $82,5 \mathrm{~b}$ & $88,7 \mathrm{~b}$ & $94,5 \mathrm{a}$ & $88,7 \mathrm{~b}$ \\
Tcap & $100,0 \mathrm{a}$ & $100,0 \mathrm{a}$ & $100,0 \mathrm{a}$ & $100,0 \mathrm{a}$ \\
Tsem & $0,0 \mathrm{~d}$ & $0,0 \mathrm{c}$ & $0,0 \mathrm{~d}$ & $0,0 \mathrm{~d}$ \\
\hline CV (\%) & 9,62 & 8,55 & 6,29 & 6,79 \\
\hline
\end{tabular}

${ }^{(1)}$ Médias seguidas por letras iguais, nas colunas, não diferem entre si pelo teste de Scott-Knott, a 5\% de probabilidade. ${ }^{(2)}$ Descrição dos tratamentos na Tabela $1 .{ }^{(3)}$ Percentagem calculada em relação à avaliação visual da testemunha sem capina, em que zero $(0 \%)$ representa nenhum controle e cem $(100 \%)$ controle total (Asociación Latinoamericana de Malezas, 1974).
Os tratamentos com a aplicação isolada de atrazina se mantiveram menos eficientes, consequência do baixo controle que esse herbicida proporciona a espécies monocotiledôneas, como $D$. horizontalis, o que reforça a necessidade da utilização de graminicidas para a viabilização do consórcio.

Em relação aos resultados da associação de nicosulfuron com atrazina, Jakelaitis et al. (2005b), ao aplicar a dose de $8+1.500 \mathrm{~g} \mathrm{ha}^{-1}$ destes produtos, não obtiveram controle satisfatório para $D$. horizontalis. Em outro trabalho semelhante, com o aumento da dose de nicosulfuron para $12 \mathrm{~g}$, na mesma associação com atrazina, foi obtido controle de $83,3 \%$ para D. horizontalis (Jakelaitis et al., 2005a), resultado muito próximo ao obtido no tratamento $\mathrm{Nic}+\mathrm{Atr}$ $\left(16+800 \mathrm{~g} \mathrm{ha}^{-1}\right)$ neste trabalho.

A população média de $U$. ruziziensis na época da aplicação dos herbicidas foi de 32,4 plantas $\mathrm{m}^{-2}$, densidade considerada adequada para esse sistema de consórcio. Bernardes (2003) não encontrou interferência significativa na produção do milho consorciado com $U$. decumbens na densidade de 20 a 40 sementes viáveis da forrageira por metro quadrado.

Na primeira avaliação de seletividade dos herbicidas para $U$. ruziziensis, aos sete DAA, foi verificada alta fitotoxicidade nos tratamentos que continham os inibidores da HPPD na sua composição, principalmente o tembotrione, seguido pelos tratamentos com mesotrione (Tabela 3). Como a enzima HPPD age na biossíntese dos carotenoides (Senseman, 2007), os sintomas típicos de fitotoxicidade provocados pelos herbicidas que inibem essa enzima são o branqueamento das folhas, que podem evoluir para a necrose dos tecidos afetados e até a morte da própria planta, se esta for sensível ao herbicida (Williams \& Pataky, 2008). Os tratamentos com nicosulfuron e atrazina, isolados ou em combinação, resultaram em baixa fitotoxicidade para U. ruziziensis.

Aos 14 DAA, os tratamentos com atrazina, nas duas doses (800 e $1.200 \mathrm{~g} \mathrm{ha}^{-1}$ ), compuseram o grupo de herbicidas mais seletivos para a $U$. ruziziensis, e não se diferenciaram das testemunhas sem controle químico. Esse resultado comprova a boa seletividade da atrazina para as braquiárias, o que já havia sido observado por Martins et al. (2007) em aplicações de $3.000 \mathrm{~g} \mathrm{ha}^{-1}$ desse herbicida, em cultivo isolado de $U$. brizantha e U. decumbens, e por Freitas et al. (2005) em aplicação 
de $1.500 \mathrm{~g} \mathrm{ha}^{-1}$ em cultivo consorciado de milho para silagem e $U$. brizantha.

Aos 14 DAA, o branqueamento foliar permaneceu pronunciado nos tratamentos com tembotrione, que se mantiveram os menos seletivos. Nos tratamentos com mesotrione, houve recuperação na coloração das folhas inicialmente branqueadas, o que resultou em fitotoxicidade média a leve. Nos tratamentos com nicosulfuron, ocorreu o oposto, tendo-se observado aumento das injúrias em comparação à primeira avaliação, para os tratamentos de Nic+Atr $\left(16+800 \mathrm{~g} \mathrm{ha}^{-1}\right)$ e Nic+Atr $\left(20+800 \mathrm{~g} \mathrm{ha}^{-1}\right)$, já que os sintomas típicos da inibição da enzima ALS, como o amarelecimento das folhas e a necrose dos pontos de crescimento, geralmente são mais pronunciados entre 7 e 12 dias após a aplicação destes herbicidas (Shim et al., 2003).

A tendência dos resultados de fitotoxicidade dos herbicidas para U. ruziziensis foi mantida na avaliação aos 28 DAA. Os tratamentos com tembotrione foram os menos seletivos: o branqueamento evoluiu para a necrose e a morte de folhas. Na sequência, ficaram os tratamentos com nicosulfuron, cujo amarelecimento das folhas também evoluiu para necrose, associado à grande redução no crescimento das plantas, nos quais foram atingidos níveis de injúrias entre 80 e 81,2\%. Martins et al. (2007) observaram sintomas semelhantes de fitotoxicidade do nicosulfuron, ao comparar a seletividade desse herbicida com imazetapyr, chlorimuron, bentazon e atrazina para a produção de $U$. brizantha; o tratamento com nicosulfuron provocou as maiores injúrias visuais na forrageira.

$\mathrm{Na}$ última avaliação, aos $42 \mathrm{DAA}$, foi constatado que a maior dose de tembotrione com atrazina $\left(75+1.000 \mathrm{~g} \mathrm{ha}^{-1}\right)$ foi o tratamento com a menor seletividade para $U$. ruziziensis, seguido pelos outros tratamentos com tembotrione, isolado ou associado à atrazina. O grupo dos tratamentos com nicossulfuron também manteve níveis altos de fitotoxicidade, entre 71,2 e $72,5 \%$. As associações de mesotrione e atrazina, assim como o tratamento com atrazina isolada, foram seletivas para $U$. ruziziensis, com níveis de fitotoxicidade abaixo de $9 \%$.

Os tratamentos com atrazina isolada, nas duas doses (800 e $1.200 \mathrm{~g} \mathrm{ha}^{-1}$ ), e a associação das menores doses de mesotrione com atrazina (Mes+Atr, 60+800 $\mathrm{g} \mathrm{ha}^{-1}$ e Mes+Atr, $90+800 \mathrm{~g} \mathrm{ha}^{-1}$ ) não se diferenciaram das testemunhas sem aplicação de herbicidas, quanto à massa de matéria seca (Tabela 3). Esses tratamentos proporcionaram maior produção de matéria seca de $U$. ruziziensis, entre $4.116,4$ e $6.024,1 \mathrm{~kg} \mathrm{ha}^{-1}$, o que comprovou ser este o grupo mais seletivo para a forrageira. Ceccon et al. (2010) também não observaram diferenças entre os tratamentos com atrazina $\left(1.760 \mathrm{~g} \mathrm{ha}^{-1}\right)$, mesotrione $\left(60 \mathrm{~g} \mathrm{ha}^{-1}\right)$ e a associação de atrazina com mesotrione $\left(880+60 \mathrm{~g} \mathrm{ha}^{-1}\right)$,

Tabela 3. Fitotoxicidade dos herbicidas a Urochloa ruziziensis, aos 7, 14, 28 e 42 dias após a aplicação (DAA) dos herbicidas, e massa de matéria seca (MS) produzida por U. ruziziensis até a colheita do milho safrinha ${ }^{(1)}$.

\begin{tabular}{|c|c|c|c|c|c|}
\hline \multirow[t]{2}{*}{ Tratamento $^{(2)}$} & \multicolumn{4}{|c|}{ Fitotoxicidade a $U$. ruziziensis $(\%)^{(3)}$} & \multirow{2}{*}{$\begin{array}{c}\mathrm{MS} \\
\left(\mathrm{kg} \mathrm{ha}^{-1}\right)\end{array}$} \\
\hline & $7 \mathrm{DAA}$ & $14 \mathrm{DAA}$ & $28 \mathrm{DAA}$ & $42 \mathrm{DAA}$ & \\
\hline$\overline{M e s}+\operatorname{Atr}(60+800)$ & $51,2 b$ & $12,5 \mathrm{c}$ & $5,0 \mathrm{e}$ & $2,5 \mathrm{c}$ & $4.919,6 \mathrm{a}$ \\
\hline Mes+Atr $(90+800)$ & $58,7 \mathrm{~b}$ & $16,2 \mathrm{c}$ & $7,5 \mathrm{~d}$ & $5,0 \mathrm{~d}$ & $4.116,4 \mathrm{a}$ \\
\hline Mes $+A \operatorname{tr}(120+800)$ & $73,7 \mathrm{a}$ & $18,7 \mathrm{c}$ & $15,0 \mathrm{c}$ & $8,7 \mathrm{~d}$ & $2.961,8 \mathrm{~b}$ \\
\hline Mes $+\operatorname{Atr}(60+1.200)$ & $53,7 \mathrm{~b}$ & $13,7 \mathrm{c}$ & $7,5 \mathrm{~d}$ & $2,5 \mathrm{e}$ & $2.861,4 \mathrm{~b}$ \\
\hline $\operatorname{Atr}(800)$ & $1,2 \mathrm{c}$ & $2,5 \mathrm{~d}$ & $2,5 \mathrm{e}$ & $0,0 \mathrm{e}$ & $6.024,1 \mathrm{a}$ \\
\hline $\operatorname{Atr}(1.200)$ & $3,7 \mathrm{c}$ & $3,7 d$ & $3,0 \mathrm{e}$ & $1,2 \mathrm{e}$ & $5.582,3 \mathrm{a}$ \\
\hline Tem (75) & $86,2 \mathrm{a}$ & $88,7 \mathrm{a}$ & $86,2 \mathrm{a}$ & $77,5 b$ & $753,0 \mathrm{c}$ \\
\hline Tem (100) & $86,2 \mathrm{a}$ & $86,2 \mathrm{a}$ & $91,7 \mathrm{a}$ & $78,7 \mathrm{~b}$ & $461,8 \mathrm{c}$ \\
\hline $\operatorname{Tem}+\operatorname{Atr}(50+1.000)$ & $83,7 \mathrm{a}$ & $85,0 \mathrm{a}$ & $86,2 \mathrm{a}$ & $77,5 \mathrm{~b}$ & $893,5 \mathrm{c}$ \\
\hline $\mathrm{Tem}+\operatorname{Atr}(75+1.000)$ & $86,2 \mathrm{a}$ & $91,2 \mathrm{a}$ & $90,5 \mathrm{a}$ & $85,0 \mathrm{a}$ & $240,9 c$ \\
\hline $\mathrm{Nic}+$ Atr $(16+800)$ & $7,5 \mathrm{c}$ & $55,0 \mathrm{~b}$ & $81,2 b$ & $71,2 \mathrm{c}$ & $1.355,4 \mathrm{c}$ \\
\hline $\mathrm{Nic}+\mathrm{Atr}(20+800)$ & $17,5 \mathrm{c}$ & $58,7 \mathrm{~b}$ & $80,0 \mathrm{~b}$ & $72,5 \mathrm{c}$ & $833,3 c$ \\
\hline Tcap & $0,0 \mathrm{c}$ & $0,0 \mathrm{~d}$ & $0,0 \mathrm{e}$ & $0,0 \mathrm{e}$ & $6.255,0 \mathrm{a}$ \\
\hline Tsem & $0,0 \mathrm{c}$ & $0,0 \mathrm{~d}$ & $0,0 \mathrm{e}$ & $0,0 \mathrm{e}$ & $6.074,3 \mathrm{a}$ \\
\hline CV (\%) & 21,21 & 16,23 & 11,90 & 11,85 & 79,56 \\
\hline
\end{tabular}

${ }^{(1)}$ Médias seguidas por letras iguais, nas colunas, não diferem entre si pelo teste de Scott-Knott, a $5 \%$ de probabilidade. ${ }^{(2)}$ Descrição dos tratamentos na Tabela 1. ${ }^{(3)}$ Percentagem calculada em relação à avaliação visual da testemunha sem capina, em que zero ( $\left.0 \%\right)$ representa nenhum controle e cem (100\%) controle total (Asociación Latinoamericana de Malezas, 1974). 
quanto à seletividade para $U$. ruziziensis cultivada em consórcio com milho safrinha; porém, os tratamentos reduziram a biomassa da forrageira, em comparação à testemunha sem aplicação de herbicidas.

Apesar de não haver diferença de fitotoxicidade entre os tratamentos com mesotrione, o tratamento com a maior dose desse herbicida (Mes+Atr, 120+800 $\mathrm{g} \mathrm{ha}^{-1}$ ) e o com a maior dose de atrazina na associação (Mes+Atr, 60+1.200 $\mathrm{g} \mathrm{ha}^{-1}$ ) proporcionaram redução da biomassa de $U$. ruziziensis.

O grupo de herbicidas que proporcionou a maior redução no desenvolvimento de caules e folhas da $U$. ruziziensis, de até $96,4 \%$, foi composto por tembotrione e nicosulfuron, que foram os mais fitotóxicos. Em trabalho com U. brizantha, Freitas et al. (2005) já haviam observado a interferência do nicosulfuron, na dose de $4 \mathrm{~g} \mathrm{ha}^{-1}$, na produção da biomassa da forrageira. Jakelaitis et al. (2005a) também constataram que o nicosulfuron, a partir de $4 \mathrm{~g} \mathrm{ha}^{-1}$ na associação com $1.500 \mathrm{~g} \mathrm{ha}^{-1}$ de atrazina, reduziu a biomassa de $U$. brizantha consorciada com milho.

A presença das plantas daninhas não resultou em diminuição da biomassa de $U$. ruziziensis, pois não houve diferença significativa quanto ao desenvolvimento da forrageira entre a testemunha com controle manual das infestantes e a testemunha sem controle. Isso demonstra que esta espécie possui boa capacidade de competição com as plantas daninhas estudadas.

Todos os tratamentos foram considerados seletivos para a cultura do milho (Tabela 4). Na primeira avaliação, aos sete DAA, não foi observada injúria alguma para os dois tratamentos com atrazina isolada. Nos tratamentos com mesotrione e tembotrione, houve leve branqueamento em poucas folhas, em algumas plantas de milho. Nos tratamentos com nicosulfuron, foi observado leve amarelecimento em algumas folhas, de forma esparsa, nas parcelas experimentais.

Com o aumento do período após a aplicação, as poucas injúrias diminuíram ainda mais, e todos os tratamentos ficaram abaixo de $2,5 \%$ de fitotoxicidade na avaliação aos 14 DAA. A partir dos 28 DAA, houve recuperação total nos tratamentos, e não foi observado mais nenhum sintoma de fitotoxicidade dos herbicidas para as plantas de milho. Karam et al. (2009) também avaliaram a fitotoxicidade dos herbicidas estudados neste trabalho para o híbrido BRS 1030 e verificaram que a aplicação isolada de mesotrione, nicosulfuron, tembotrione e as associações destes com atrazina causaram níveis de injúrias de no máximo 1,7\%, o que comprova a seletividade dos tratamentos para este híbrido.

Tabela 4. Fitotoxicidade dos herbicidas para o milho safrinha, aos 7, 14 e 28 dias após a aplicação (DAA), e produtividade do milho nos tratamentos com ou sem Urochloa ruziziensis ${ }^{(1)}$.

\begin{tabular}{|c|c|c|c|c|c|}
\hline \multirow[t]{2}{*}{ Tratamento $^{(2)}$} & \multicolumn{3}{|c|}{ Fitotoxicidade $(\%)^{(3)}$} & \multicolumn{2}{|c|}{ Produtividade $\left(\mathrm{kg} \mathrm{ha}^{-1}\right)$} \\
\hline & 7 DAA & $14 \mathrm{DAA}$ & $28 \mathrm{DAA}$ & Com & Sem \\
\hline $\mathrm{Mes}+\mathrm{Atr}(60+800)$ & $5,0 \mathrm{~b}$ & $1,3 b$ & $0,0 \mathrm{a}$ & $5.400 \mathrm{Aa}$ & $5.893,4 \mathrm{Aab}$ \\
\hline $\mathrm{Mes}+\mathrm{Atr}(90+800)$ & $5,3 b$ & $2,0 \mathrm{~b}$ & $0,0 \mathrm{a}$ & $5.702 \mathrm{Aa}$ & $6.281,7 \mathrm{Aa}$ \\
\hline $\mathrm{Mes}+\mathrm{Atr}(120+800)$ & $6,8 \mathrm{~b}$ & $2,3 b$ & $0,0 \mathrm{a}$ & $5.906 \mathrm{Aa}$ & $5.844,3 \mathrm{Aab}$ \\
\hline $\mathrm{Mes}+\operatorname{Atr}(60+1.200)$ & $4,3 b$ & $1,0 \mathrm{~b}$ & $0,0 \mathrm{a}$ & $6.193 \mathrm{Aa}$ & $6.233,4 \mathrm{Aa}$ \\
\hline Atr (800) & $0,0 \mathrm{a}$ & $0,0 \mathrm{a}$ & $0,0 \mathrm{a}$ & $5.793 \mathrm{Aa}$ & $5.929,1 \mathrm{Aab}$ \\
\hline $\operatorname{Atr}(1.200)$ & $0,0 \mathrm{a}$ & $0,0 \mathrm{a}$ & $0,0 \mathrm{a}$ & $5.761 \mathrm{Aa}$ & $6.373,0 \mathrm{Aa}$ \\
\hline Tem (75) & $1,3 \mathrm{a}$ & $0,8 \mathrm{a}$ & $0,0 \mathrm{a}$ & $5.713 \mathrm{Aa}$ & $6.242,6 \mathrm{Aa}$ \\
\hline Tem (100) & $2,8 \mathrm{a}$ & $1,5 \mathrm{~b}$ & $0,0 \mathrm{a}$ & $6.287 \mathrm{Aa}$ & $5.900,3 \mathrm{Aab}$ \\
\hline Tem+Atr $(50+1.000)$ & $3,8 \mathrm{~b}$ & $1,5 \mathrm{~b}$ & $0,0 \mathrm{a}$ & 5.913Aa & $6.067,2 \mathrm{Aa}$ \\
\hline Tem+Atr $(75+1.000)$ & $4,3 b$ & $1,8 \mathrm{~b}$ & $0,0 \mathrm{a}$ & $6.291 \mathrm{Aa}$ & $5.909,8 \mathrm{Aab}$ \\
\hline $\mathrm{Nic}+\operatorname{Atr}(16+800)$ & $3,8 b$ & $1,8 \mathrm{~b}$ & $0,0 \mathrm{a}$ & $5.852 \mathrm{Aa}$ & $6.166,8 \mathrm{Aa}$ \\
\hline $\mathrm{Nic}+\operatorname{Atr}(20+800)$ & $4,8 b$ & $2,3 b$ & $0,0 \mathrm{a}$ & $6.068 \mathrm{Aa}$ & $5.976,2 \mathrm{Aa}$ \\
\hline Tcap & $0,0 \mathrm{a}$ & $0,0 \mathrm{a}$ & $0,0 \mathrm{a}$ & $3.566 \mathrm{Bb}$ & $6.523,0 \mathrm{Aa}$ \\
\hline Tsem & $0,0 \mathrm{a}$ & $0,0 \mathrm{a}$ & $0,0 \mathrm{a}$ & $3.397 \mathrm{Ab}$ & $4.601,2 \mathrm{Ab}$ \\
\hline Média & - & - & - & $5.556 \mathrm{~B}$ & $5.996 \mathrm{~A}$ \\
\hline CV (\%) & 19,62 & 16,48 & - & 15,87 & \\
\hline
\end{tabular}

${ }^{(1)}$ Médias seguidas por letras iguais, minúsculas nas colunas e maiúsculas nas linhas, não diferem entre si pelo teste t, a $5 \%$ de probabilidade. ${ }^{(2)}$ Descrição dos tratamentos na Tabela $1 .{ }^{(3)}$ Percentagem calculada em relação à avaliação visual da testemunha sem capina, em que zero ( $\left.0 \%\right)$ representa nenhum controle e cem (100\%) controle total (Asociación Latinoamericana de Malezas, 1974). 
Quanto à produtividade do milho nos tratamentos sem U. ruziziensis, as pequenas diferenças visuais observadas no controle das infestantes entre os tratamentos químicos não resultaram em diminuição na produtividade da cultura, o que indica que os níveis de controle foram eficientes em evitar perdas para o milho.

$\mathrm{Na}$ avaliação da interferência de $U$. ruziziensis sobre a cultura do milho, observou-se que, quando a espécie não sofreu nenhum tipo de controle, a competição causou redução na produtividade de 45,3\%, em comparação com as testemunhas com controle manual das plantas daninhas.

Trabalhos sobre o consórcio de milho com braquiária podem indicar diminuição de produtividade do milho pela competição com a forrageira, como o realizado por Portes et al. (2000), ou mostrar que a braquiária pode não interferir na produção da cultura, como constataram Freitas et al. (2008) e Ceccon et al. (2010).

A supressão proporcionada por cada tratamento químico foi eficiente para evitar a competição da $U$. ruziziensis com a cultura do milho, pois não houve diferença significativa na produtividade entre os tratamentos químicos, com ou sem a forrageira (Tabela 4).

\section{Conclusões}

1. A consorciação entre o milho safrinha e Urochloa ruziziensis é viável agronomicamente mas, se a supressão do desenvolvimento da braquiária não for realizada por herbicidas, há diminuição da produtividade do milho safrinha no consórcio.

2. As associações de mesotrione e atrazina, nas doses de 60+800, 90+800, 120+800 e 60+1.200 $\mathrm{g} \mathrm{ha}^{-1}$, são opções de manejo químico para o consórcio milho safrinha e $U$.ruziziensis.

\section{Referências}

ADEGAS, F.S. Girassol (Helianthus annuus L.) resistente as imidazolinonas: obtenção de genótipo e manejo de plantas daninhas. 2005. 98p. Tese (Doutorado) - Universidade Estadual de Londrina, Londrina.

ASOCIACIÓN LATINOAMERICANA DE MALEZAS. Recomendaciones sobre unificación de los sistemas de evaluación en ensayos de control de malezas. ALAM, v.1, p.35-38, 1974.

BERNARDES, L.F. Semeadura de capim-braquiaria em pós-emergência da cultura do milho para obtenção de cobertura morta em sistema de plantio direto. 2003. 42p. Dissertação (Mestrado) - Universidade Estadual Paulista, Jaboticabal.
BEUTLER, A.N.; CENTURION, J.F. Compactação do solo no desenvolvimento radicular e na produtividade da soja. Pesquisa Agropecuária Brasileira, v.39, p.581-588, 2004.

BRASIL. Ministério da Agricultura, Pecuária e Abastecimento. Agrofit: sistema de agrotóxicos fitossanitários. Disponível em: $<$ http://extranet.agricultura.gov.br/agrofit_cons/principal_agrofit_ cons>. Acesso em: 13 jul. 2010.

BRIGHENTI, A.M.; CASTRO, C.; GAZZIERO, D.L.P.; ADEGAS, F.S.; VOLL, E. Cadastramento fitossociológico de plantas daninhas na cultura do girassol. Pesquisa Agropecuária Brasileira, v.38, p.651-657, 2003.

CECCON, G. Milho safrinha com solo protegido e retorno econômico em Mato Grosso do Sul. Revista Plantio Direto, v.16, p.17-20, 2007.

CECCON, G.; MATOSO, A.O.; NETO NETO, A.L.; PALOMBO, L. Uso de herbicidas no consórcio de milho safrinha com Brachiaria ruziziensis. Planta Daninha, v.28, p.359-364, 2010.

CECCON, G.; SACOMAN, A.; MATOSO, A. de O.; NUNES, D.P.; INOCÊNCIO, M.F. Consórcio de milho safrinha com Brachiaria ruziziensis, em lavouras comerciais de agricultores em 2008. Dourados: Embrapa Agropecuária Oeste, 2008. 28p. (Embrapa Agropecuária Oeste. Boletim de pesquisa, 48).

CHRISTOFFOLETI, P.J.; LÓPEZ-OVEJERO, R.F.; CARVALHO, J.C. Aspectos da resistência de plantas daninhas a herbicidas. Londrina: Associação Brasileira de Ação a Resistência de Plantas Daninhas aos Herbicidas, 2003. 90p.

COMPANHIA NACIONAL DE ABASTECIMENTO. Acompanhamento da safra brasileira: grãos, décimo levantamento, julho de 2009. Brasília: CONAB, 2009. 39p.

DUARTE, A.P.; SILVA, A.; DEUBER, R. Plantas infestantes em lavouras de milho safrinha, sob diferentes manejos no Médio Paranapanema. Planta Daninha, v.25, p.285-291, 2007.

FRANCHINI, J.C.; SARAIVA, O.F.; DEBIASI, H.; GONÇALVES, S.L. Contribuição de sistemas de manejo do solo para a produção sustentável da soja. Londrina: Embrapa Soja, 2008. 12p. (Embrapa Soja. Circular técnica, 58).

FREITAS, F.C.L.; FERREIRA, F.A.; FERREIRA, L.R.; SANTOS, M.V.; AGNES, E.L. Cultivo consorciado de milho para silagem com Brachiaria brizantha no sistema de plantio convencional. Planta Daninha, v.23, p.635-644, 2005.

FREITAS, F.C.L.; SANTOS, M.V.; MACHADO, A.F.L.; FERREIRA, L.R.; FREITAS, M.A.M.; SILVA, M.G.O. Comportamento de cultivares de milho no consórcio com Brachiaria brizantha na presença e ausência de Foramsulfuron + Iodosulfuron-Methyl para o manejo da forrageira. Planta Daninha, v.26, p.215-221, 2008.

JAKELAITIS, A.; SILVA, A.A.; FERREIRA, L.R.; SILVA, A.F.; FERREIRA, J.L.; VIANA, R.G. Efeito de herbicidas no consórcio de milho com Brachiaria brizantha. Planta Daninha, v.23, p.69-78, 2005a.

JAKELAITIS, A.; SILVA, A.F.; SILVA, A.A.; FERREIRA, L.R.; FREITAS, F.C.L.; VIVIAN, R. Influência de herbicidas e de sistemas de semeadura de Brachiaria brizantha consorciada com milho. Planta Daninha, v.23, p.59-67, 2005b. 
KARAM, D.; CRUZ, M.B. Características do herbicida mesotrione na cultura do milho. Sete Lagoas: Embrapa Milho e Sorgo, 2004. 4p. (Embrapa Milho e Sorgo. Circular técnica, 52).

KARAM, D.; MELHORANÇA, A.L. Plantas daninhas. In: CRUZ, J.C. Cultivo do milho. 5.ed. Sete Lagoas: Embrapa Milho e Sorgo, 2009. (Embrapa Milho e Sorgo. Sistemas de produção, 2).

KARAM, D.; SILVA, J.A.A.; FILHO, I.A.P.; MAGALHÃES, P.C. Características do herbicida tembotrione na cultura do milho. Sete Lagoas: Embrapa Milho e Sorgo, 2009. 6p. (Embrapa Milho e Sorgo. Circular técnica, 129).

MACEDO, M.C.M. Integração lavoura e pecuária: o estado da arte e inovações tecnológicas. Revista Brasileira de Zootecnia, v.38, p.133-146, 2009. Número especial.

MARTINS, D.; TRIGUERO, L.R.C.; DOMINGOS, V.D.; MARTINS, C.C.; MARCHI, S.R.; COSTA, N.V. Seletividade de herbicidas aplicados em pós-emergência sobre capim-braquiária.

Revista Brasileira de Zootecnia, v.36, p.1969-1974, 2007.
PORTES, T.A.; CARVALHO, S.I.C.; OLIVEIRA, I.P.; KLUTHCOUSKI, J. Análise de crescimento de uma cultivar de braquiária em cultivo solteiro e consorciado com cereais. Pesquisa Agropecuária Brasileira, v.35, p.1349-1358, 2000.

RODRIGUES, B.N.; ALMEIDA, F.S. de. Guia de herbicidas. 5.ed. Londrina: Edição dos autores, 2005. 592p.

SENSEMAN, S.A. Herbicide handbook. $9^{\text {th }}$ ed. Lawrence: Weed Science Society of America, 2007. 521p.

SHIM, S.I.; LEE, B.M.; RYU, E.I.; KANG, B.H. Response of leaf acetolactase synthase from different leaf positions and seedlings age to sulfonylureia herbicide. Pesticide Biochemistry and Physiology, v.75, p.39-46, 2003.

TORRES, E.; SARAIVA, O.F. Camadas de impedimento mecânico do solo em sistemas agrícolas com a soja. Londrina: Embrapa Soja, 1999. 58 p. (Embrapa Soja. Circular técnica, 23).

WILLIAMS, M.M.; PATAKY, J.K. Genetic basis of sensitivity in sweet corn to tembotrione. Weed Science, v.56, p.364-370, 2008.

Recebido em 1ㅇ de agosto de 2010 e aprovado em 22 de julho de 2011 